\title{
Complexation and Redox Interactions Between Aqueous Plutonium and Manganese Oxide Interfaces
}

\author{
Dawn SHAUGHNESSY ${ }^{1 *}$, Heino Nitsche ${ }^{1,2}$, Corwin Booth ${ }^{1}$, David Shuh ${ }^{1}$, Glenn Waychunas ${ }^{3}$, Richard Wilson ${ }^{1,2}$, \\ Kirk Cantrell ${ }^{4}$, and R. Jeffrey Serne ${ }^{4}$ \\ ${ }^{I}$ Chemical Sciences Division, the Glenn T. Seaborg Center, Lawrence Berkeley National Laboratory, Berkeley, CA, 94720 , \\ USA \\ ${ }^{2}$ Department of Chemistry, University of California, Berkeley, CA, 94720, USA \\ ${ }^{3}$ Earth Sciences Division, Lawrence Berkeley National Laboratory, Berkeley, CA, 94720, USA \\ ${ }^{4}$ Applied Geology and Geochemistry, Pacific Northwest National Laboratory, Richland, WA, 99352, USA
}

\begin{abstract}
The sorption of $\mathrm{Pu}(\mathrm{VI})$ and $\mathrm{Pu}(\mathrm{V})$ onto manganite $(\mathrm{MnOOH})$ and Hausmannite $\left(\mathrm{Mn}_{3} \mathrm{O}_{4}\right)$ was studied at $\mathrm{pH} 5$. Manganite sorbed $21-24 \%$ from a $1 \times 10^{-4} \mathrm{M}$ plutonium solution and the hausmannite removed between $43-66 \%$ of the plutonium. The increased sorption by hausmannite results from its larger surface area (about twice that of manganite) plus a larger number of active surface sites. X-ray absorption near-edge structure (XANES) spectra taken at the Pu LIII edge were compared to standard spectra of plutonium in single oxidation states. Based on these spectra, it appears that both manganite and hausmannite reduce the higher valent plutonium species to $\mathrm{Pu}(\mathrm{IV})$. Between $53-59 \%$ of the plutonium was present as $\mathrm{Pu}(\mathrm{IV})$ in the manganite samples while $55-61 \%$ of the plutonium complexed to the hausmannite had also been reduced to $\mathrm{Pu}(\mathrm{IV})$. The exact mechanism behind this redox interaction between the plutonium and the manganese needs to be identified.
\end{abstract}

\section{KEYWORDS: Plutonium, manganese, manganite, hausmannite, XANES}

\section{Introduction}

Several U.S. Department of Energy sites have been contaminated by plutonium as a result of weapons related activities. Plutonium is highly toxic and potentially mobile in aquatic environments. To predict its potential hazards, reliable models of plutonium migration through the vadose zone to nearby groundwater supplies are required. Fundamental knowledge of the interfacial reactions between plutonium and the surrounding geomaterial is essential for understanding its transport in the environment.

Previous studies have illustrated that plutonium will sorb to iron oxyhydroxides and other naturally occurring materials, possibly retarding its migration through the environment. ${ }^{1,2)}$ Recent synchrotron based X-ray microprobe studies have shown that manganese oxides, present as minor phases in the environment, can preferentially sequester plutonium over iron oxides present in larger quantities. ${ }^{3-5)}$ Based on these developments, it is essential that the interactions between plutonium and manganese oxyhydroxides be thoroughly understood to design effective transport models and efficient plutonium remediation systems.
We have begun a systematic study of the interfacial reactions between plutonium and manganese oxyhydroxide mineral surfaces. The interaction of $\mathrm{Pu}(\mathrm{V})$ and $\mathrm{Pu}(\mathrm{VI})$ with manganite $(\mathrm{Mn}(\mathrm{III}) \mathrm{OOH})$ and hausmannite $\left(\mathrm{Mn}(\mathrm{II}) \mathrm{Mn}(\mathrm{III})_{2} \mathrm{O}_{4}\right)$ has been studied using several analytical methods. Manganite and hausmannite were chosen as representative examples of minerals typically found in vadose zone conditions underneath the Hanford tank farm. ${ }^{6,7)}$ The information gained from these investigations will ultimately be incorporated into models that will be used to predict the migration of plutonium contaminants in the environment.

\section{Experimental Procedure}

Manganite and hausmannite were supplied by Chemetals, Incorporated (Baltimore, MD) as dry powders and were used without additional treatment. The minerals were crushed and the 63-212 $\mu \mathrm{m}$ size fraction was collected. Powder X-ray diffraction patterns taken with a Siemens D-500 diffractometer showed that no impurities or alternate mineral phases were present within the detection limits of the method. The mineral surface areas were determined

\footnotetext{
* Corresponding author, Tel. +1-510-486-7307

Fax. +1-510-486-7444

E-mail: dakeeney@lbl.gov
} 
using a standard B.E.T. method with an out-gassing temperature of $150^{\circ} \mathrm{C}$.

$\mathrm{Pu}(\mathrm{VI})$ was prepared by refluxing a stock solution of plutonium in concentrated $\mathrm{HClO}_{4}$ at $190^{\circ}$ for 4 hours. Any traces of organic materials were destroyed before the addition of $\mathrm{HClO}_{4}$ by evaporating the solution with concentrated $\mathrm{HNO}_{3}$ to near dryness. $\mathrm{Pu}(\mathrm{V})$ was formed by electrochemically reducing $\mathrm{Pu}(\mathrm{VI})$ according to the method of Cohen. ${ }^{8)}$ Plutonium oxidation states were verified prior to use through optical absorption spectroscopy measured with an Ocean Optics S2000 fiber optic spectrometer. ${ }^{9)}$ Samples were prepared by shaking diluted plutonium stock solutions with either $250 \mathrm{mg}$ of manganite or $100 \mathrm{mg}$ of hausmannite in $0.1 \mathrm{M} \mathrm{NaClO}_{4}$. $\mathrm{pH}$ values were adjusted using $\mathrm{NaOH}$ or $\mathrm{HClO}_{4}$ of various concentrations. After 24 hours of contact, the samples were filtered onto $3 \mu \mathrm{m}$ cellulose membrane filters, which were then placed in heat-sealed polyethylene bags for containment.

X-ray absorption near-edge structure (XANES) spectra were collected on the $\mathrm{Pu} \mathrm{L}_{\mathrm{III}}$ edge at the Stanford Synchrotron Radiation Laboratory (SSRL) on wiggler beam line 4-1 using a half-tuned $\mathrm{Si}$ (220) double-crystal monochromator. Fluorescence yield spectra were collected with a four-pixel Ge fluorescence detector. ${ }^{10)}$ Energy calibrations were performed simultaneously by measuring transmission data from a $\mathrm{PuO}_{2}$ reference. The pre-edge background was removed such that the absorption well above the $\mathrm{Pu} \mathrm{L}_{\mathrm{III}}$ edge followed a Victoreen formula. All data from the Ge detector were corrected for dead time prior to data reduction.

\section{Results and discussions}

Figure 1 illustrates the (a) manganite and (b) hausmannite mineral structures. Manganite has a structure similar to that of rutile ${ }^{11)}$ and is composed of rows of edge-sharing $\mathrm{Mn}(\mathrm{O}, \mathrm{OH})_{6}$ octahedra. ${ }^{12}$ Unlike rutile, the octahedra are considerably distorted. Hausmannite has a tetragonally-distorted spinel structure ${ }^{12)}$ with most Mn(III) in octahedral sites and $\mathrm{Mn}(\mathrm{II})$ in tetrahedral coordination. In solution, the surface functional groups of both minerals are hydroxyl groups, which can be protonated or deprotonated depending on the $\mathrm{pH}$ of the solution.

$\mathrm{Pu}(\mathrm{VI})$ and $\mathrm{Pu}(\mathrm{V})$ were sorbed to manganite and hausmannite at a $\mathrm{pH}$ of 5 from an initial plutonium concentration of $1 \times 10^{-4} \mathrm{M}$. Before the preparation of the XANES samples described above, the amount of plutonium complexed with the minerals was determined via liquid scintillation counting by measuring the plutonium remaining in solution. After 24 hours of contact, the manganite sorbed $21 \pm 1 \%$ of the $\mathrm{Pu}(\mathrm{VI})$ and $24 \pm 1 \%$ of the $\mathrm{Pu}(\mathrm{V})$. Likewise, the hausmannite removed $43 \pm 1 \%$ of $\mathrm{Pu}(\mathrm{VI})$ and $66 \pm 1 \%$ of $\mathrm{Pu}(\mathrm{V})$ from the solution. Previous kinetic experiments had shown that the uptake of plutonium was complete after 24 hours of contact time.

The hausmannite sorbed approximately 2-3 times the amount of plutonium than the manganite under the same conditions. This is due to the larger surface area of hausmannite, which was found using the B.E.T. method to be $20.4 \pm 0.8 \mathrm{~m}^{2} / \mathrm{g}$ compared to $9.5 \pm 1.4 \mathrm{~m}^{2} / \mathrm{g}$ for manganite. There are more available surface sites per unit area for binding to plutonium, resulting in a larger overall amount of plutonium sorption with hausmannite.

XANES measurements were also collected on standard solutions containing either $\mathrm{Pu}(\mathrm{IV}), \mathrm{Pu}(\mathrm{V})$, or $\mathrm{Pu}(\mathrm{VI})$. The oxidation state of the plutonium was verified using optical absorption spectroscopy. The incident x-ray energies for (a)

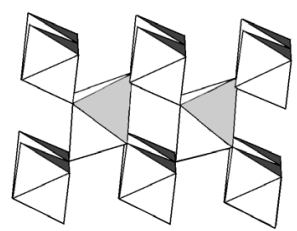

(b)

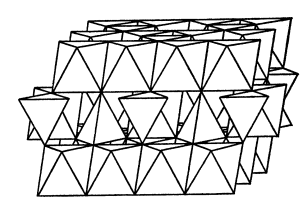

Fig. 1 Structures of (a) manganite and (b)

the data of these standard solutions were also calibrated to the $\mathrm{PuO}_{2}$ reference. Plutonium oxidation states can be determined by comparing the main $\mathrm{L}_{\mathrm{III}}$ absorption energy to known standards. ${ }^{13)}$ In addition to the energy shifts between the $\mathrm{Pu}(\mathrm{IV}), \mathrm{Pu}(\mathrm{V})$, and $\mathrm{Pu}(\mathrm{VI})$ standards and the $\mathrm{PuO}_{2}$ reference $(1.88 \pm 0.01 \mathrm{eV}, 0.17 \pm 0.01 \mathrm{eV}$, and $2.33 \pm 0.01 \mathrm{eV}$, respectively, taken from the peak in the first derivative), there is a feature on the high energy side of the white line in the $\mathrm{Pu}(\mathrm{V})$ and $\mathrm{Pu}(\mathrm{VI})$ spectra due to multiple scattering between the plutonium and the axial oxygens of the plutonyl structure. This anomalous energy shift between the $\mathrm{Pu}(\mathrm{IV})$ and $\mathrm{Pu}(\mathrm{V})$ standards has been observed previously. ${ }^{14)}$ These differences in energy and shape allow for the determination of plutonium oxidation states in the sorption samples by fitting a linear combination of the standard spectra to the experimental data between 18,000 and 18,080 eV. The small energy shift and nearly identical shape of $\mathrm{Pu}(\mathrm{V})$ and $\mathrm{Pu}(\mathrm{VI})$ make it difficult to quantify the amount of each of these oxidation states present in the unknown spectra. However, we can determine whether there is any of the plutonyl structure present without being able to distinguish between $\mathrm{Pu}(\mathrm{V}), \mathrm{Pu}(\mathrm{VI})$, or a combination of the two. The fits presented below represent our preliminary results.

Figure 2 shows the XANES spectra taken after $\mathrm{Pu}(\mathrm{VI})$ (a) and $\mathrm{Pu}(\mathrm{V})$ (b) were in contact with manganite for 24 hours, and the resulting fits to the data. The plutonium standards used in the fits are also shown for comparison. $68 \pm 5 \%$ of the initial $\mathrm{Pu}(\mathrm{VI})$ sorbed to the manganite has been reduced to $\mathrm{Pu}(\mathrm{IV})$, and approximately $67 \pm 5 \%$ of the original $\mathrm{Pu}(\mathrm{V})$ has also been reduced to $\mathrm{Pu}(\mathrm{IV})$. The best agreements were achieved by fitting the residual plutonium as $\mathrm{Pu}(\mathrm{V})$, but as discussed above, it is also possible that this residual could be $\mathrm{Pu}(\mathrm{VI})$ or a combination of both $\mathrm{Pu}(\mathrm{V})$ and $\mathrm{Pu}(\mathrm{VI})$. Likewise, Fig. 3(a) and (b) shows the results of the interaction of $\mathrm{Pu}(\mathrm{VI})$ and $\mathrm{Pu}(\mathrm{V})$ with hausmannite and the comparison to the plutonium standards. In these samples, $71 \pm 5 \%$ of the original $\mathrm{Pu}(\mathrm{VI})$ and $61 \pm 5 \%$ of the 
$\mathrm{Pu}(\mathrm{V})$ were also reduced to $\mathrm{Pu}(\mathrm{IV})$ after 24 hours of contact. The best fits were achieved by fitting the residual plutonium in each case as $\mathrm{Pu}(\mathrm{V})$. There was something wrong with the absolute energy calibration in Fig. 3(b) such that all of the plutonium standards needed to be shifted $0.92 \mathrm{eV}$ to correctly line up the references of the plutonium standards to the reference from the data. In all four spectra, however, the characteristic high-energy plutonyl feature is missing. This indicates that the plutonyl cation (either $\mathrm{Pu}(\mathrm{VI})$ or $\mathrm{Pu}(\mathrm{V}))$ is mostly reduced and is instead sorbed to the mineral surfaces as $\mathrm{Pu}(\mathrm{IV})$. Extended $\mathrm{x}$-ray absorption fine structure (EXAFS) data, which will be presented in a future publication, also give evidence for the reduction to $\mathrm{Pu}(\mathrm{IV}){ }^{15)}$ Fits to the EXAFS show that the nearest oxygen neighbors have bond lengths resembling what would be expected for $\mathrm{Pu}(\mathrm{IV})$.

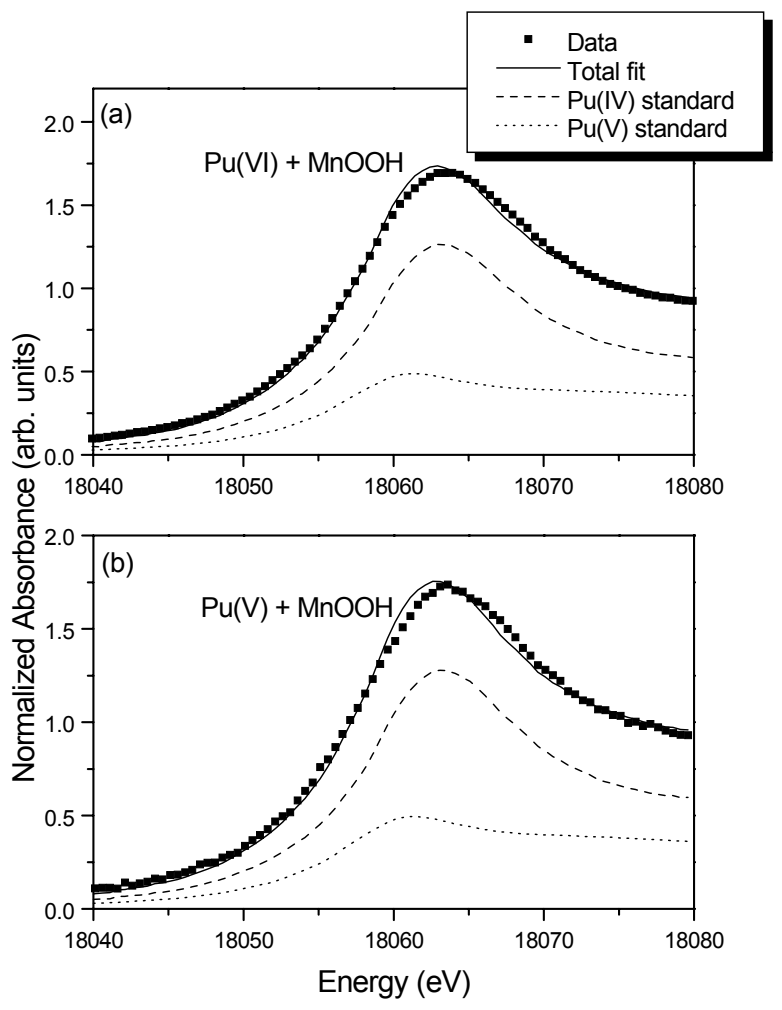

Fig. 2 XANES spectra of (a) $\mathrm{Pu}(\mathrm{VI})$ and (b) $\mathrm{Pu}(\mathrm{V})$ solutions in contact with $\mathrm{MnOOH}$ at $\mathrm{pH} 5$ for 24 hours. The plutonium standards used to fit the spectra are also shown in their relative amounts.

The exact mechanism behind the reduction of plutonium is currently unknown, however one possibility is that $\mathrm{Mn}$ (III) (or $\mathrm{Mn}$ (II) in the case of hausmannite) is directly reducing the plutonium (and therefore becoming oxidized in the process) on the mineral surface or when the plutonium in solution is in close contact with the surface. Another possibility is that the $\mathrm{Mn}(\mathrm{III})$ in these minerals is undergoing disproportionation after contact with the solution into $\mathrm{Mn}$ (II) and $\mathrm{Mn}(\mathrm{IV})$. $\mathrm{Mn}(\mathrm{II})$ (which is already present in hausmannite) is highly soluble and would likely dissolve into solution immediately after formation. The $\mathrm{Mn}(\mathrm{II})$ in solution could reduce the plutonium in solution to $\mathrm{Pu}(\mathrm{IV})$, which would then sorb to the mineral surfaces.

\section{Conclusions}

Manganite and hausmannite, which represent typical $\mathrm{Mn}$ (III) minerals found in vadose zone conditions under the Hanford tank farm, have been shown to sorb $\mathrm{Pu}(\mathrm{VI})$ and $\mathrm{Pu}(\mathrm{V})$ at $\mathrm{pH}$ 5. The hausmannite sorbs approximately 2-3 times the amount of plutonium than the manganite due to its larger surface area. The comparison of XANES spectra taken at the $\mathrm{Pu} \mathrm{L}_{\mathrm{III}}$ edge to standard solutions containing a

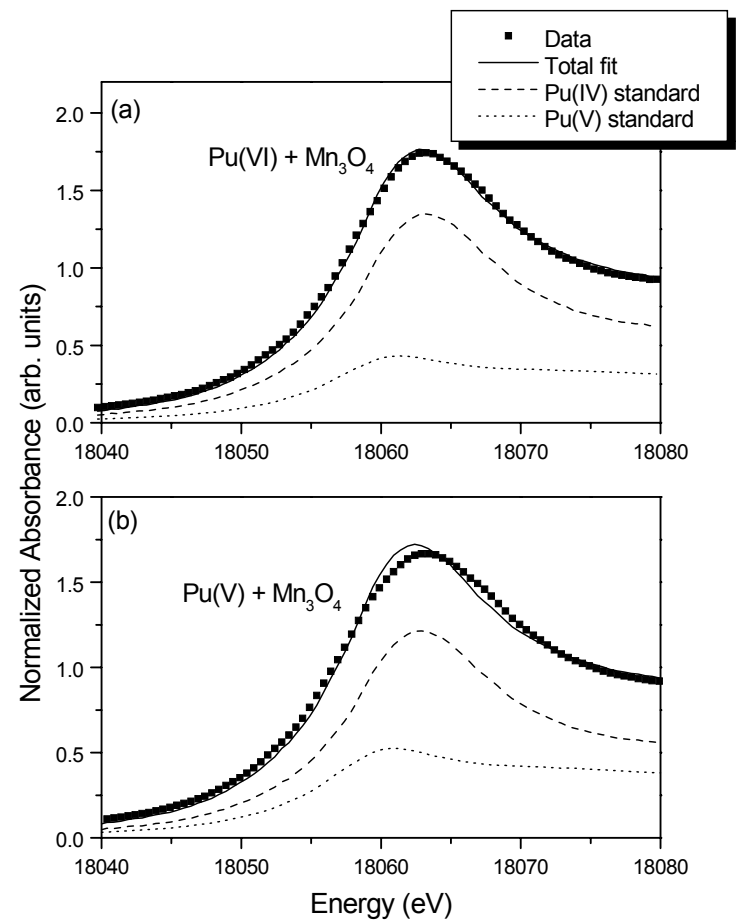

Fig. 3 XANES spectra of (a) $\mathrm{Pu}(\mathrm{VI})$ and (b) $\mathrm{Pu}(\mathrm{V})$ solutions in contact with $\mathrm{Mn}_{3} \mathrm{O}_{4}$ at $\mathrm{pH} 5$ for 24 hours. The plutonium standards used to fit the spectra are also shown in their relative amounts. The absolute energy calibration was unreliable for the data set in (b), and an overall energy shift of $0.92 \mathrm{eV}$ was allowed for the plutonium standards in the fit.

single plutonium oxidation state shows that both manganite and hausmannite reduce $\mathrm{Pu}(\mathrm{VI})$ and $\mathrm{Pu}(\mathrm{V})$ to $\mathrm{Pu}(\mathrm{IV})$ after 24 hours of contact. The mechanism responsible for the plutonium reduction could be attributed to direct reduction by $\mathrm{Mn}(\mathrm{III})$ or $\mathrm{Mn}$ (II) on the mineral surfaces or possibly from $\mathrm{Mn}(\mathrm{II})$ in solution, which would be formed as the result of disproportionation of Mn(III). Regardless of the exact mechanism governing this redox interaction between manganese and plutonium, the reduction to $\mathrm{Pu}(\mathrm{IV})$ has important environmental ramifications. For instance, $\mathrm{Pu}(\mathrm{IV})$ forms insoluble colloids, which carry a positive surface charge and have a tendency to adsorb on various 
surfaces including minerals. ${ }^{16)}$ The plutonyl cations are much more soluble and therefore more likely to migrate through the vadose zone to nearby groundwater supplies. These results are important for designing effective environmental stabilization and remediation systems because the formation of insoluble plutonium species that have a tendency to adsorb to mineral surfaces could retard its migration through the environment.

In addition to studying the mechanism governing the manganese - plutonium redox system, we are also conducting sorption studies at additional $\mathrm{pH}$ values and with other representative manganese oxyhydroxide minerals. All of these results will be incorporated into surface complexation models that will used to predict the transport of plutonium contaminants in the environment.

\section{Acknowledgments}

This work is supported by the Office of Science and Technology, within the U.S. Department of Energy (DOE), Environmental Management Science Program. Lawrence Berkeley National Laboratory (LBNL) and Pacific Northwest National Laboratory (PNNL) are operated by the DOE under contracts numbers DE-AC03-76SF00098 and DE-AC06-76RL1830, respectively. PNNL is operated by the Batelle Memorial Institute. This work was performed in part at the Stanford Synchrotron Radiation Laboratory, which is operated by the DOE, Office of Basic Energy Sciences.

The authors would like to thank the members of the Glenn T. Seaborg Center at LBNL for their assistance collecting the XAFS data.

\section{References}

1) A. L. Sanchez, J. W. Murray, and T. H. Sibley, "The adsorption of plutonium IV and V on goethite," Geochim. Cosmochim. Acta 49, 2297 (1985).

2) W. L. Keeney-Kennicutt and J. W. Morse, "The redox chemistry of $\mathrm{Pu}(\mathrm{V}) \mathrm{O}_{2}{ }^{+}$interaction with common mineral surfaces in dilute solutions and seawater," Geochim. Cosmochim. Acta 49, 2577 (1985).

3) M. C. Duff, D. B. Hunter, I. R. Triay, D. T. Reed, C. R. Cotter, P. M. Bertsch, J. Kitten, G. Shea-McCarthy, S. J. Chipera, and D. T. Vaniman, "Mineral associations and average oxidation states of sorbed Pu on tuff," Environ. Sci. Technol. 33, 2163 (1999).

4) M. C. Duff, M. Newville, D. B. Hunter, P. M. Bertsch, S. R. Sutton, I. R. Triay, D. T. Vaniman, P. Eng, and M. L. Rivers, "Micro-XAS studies with sorbed plutonium on tuff," J. Synch. Rad. 6, 50 (1999).

5) A. Manceau and J. -L. Hazemann, Personal communication (1999).

6) B. M. Tebo, W. C. Ghirose, L. G. van Waasbergen, P. L. Siering, and R. Caspi in Geomicrobiology Reviews in Mineralogy (Mineralogical Society of America, Washington, D. C., 1997), Vol. 35, p. 225.

7) R. J. Serne, J. L. Conca, V. L. LeGore, K. J. Cantrell, C. W. Lindenmeier, J. A. Campbell, J. E. Amonette, and M. I. Wood, "Solid-waste leach characteristics and contaminant-sediment interactions. Volume 1: Batch leach and adsorption tests and sediment characterization," PNL-8889 (PNNL, 1993).

8) D. Cohen, "Electrochemical studies of plutonium ions in perchloric acid solutions," J. Inorg. Nucl. Chem. 18 , 207 (1961).

9) D. Cohen, "The absorption spectra of plutonium ions in perchloric acid solutions," J. Inorg. Nucl. Chem. 18, 211 (1961).

10) J. J. Bucher, N. M. Edelstein, K. P. Osborne, D. K. Shuh, N. Madden, P. Luke, D. Pehl, C. Cork, D. Malone, and P. G. Allen, SRI '95 Conference Proceedings. Rev. Sci. Inst. 67, 1 (1996).

11) H. Dachs, "Neutronen- und Röntgenuntersuchungen am Manganit, MnOOH," Zeits. Kristallogr. 118, 303 (1963).

12) G. A. Waychunas in Reviews in Mineralogy (Mineralogical Society of America, Washington, D. C., 1991), Vol. 25, p. 11.

13) S. D. Conradson, I. Al Mahamid, D. L. Clark, N. J. Hess, E. A. Hudson, M. P. Neu, P. D. Palmer, W. H. Runde, and C. D. Tait, "Oxidation state determination of plutonium aquo ions using $\mathrm{x}$-ray absorption spectroscopy," Polyhedron 17, 599 (1998).

14) P. G. Allen, J. J. Bucher, D. K. Shuh, N. M. Edelsetin, and T. Reich, "Investigation of aquo and chloro complexes of $\mathrm{UO}_{2}{ }^{2+}, \mathrm{NpO}_{2}{ }^{+}, \mathrm{Np}^{4+}$, and $\mathrm{Pu}^{3+}$ by x-ray absorption fine structure spectroscopy," Inorg. Chem. 36, 4676 (1997).

15) D. A. Shaughnessy, C. H. Booth, H. Nitsche, D. K. Shuh, G. A. Waychunas, R. E. Wilson, H. Gill, K. J. Cantrell, and R. J. Serne, "Investigation of molecular interfacial reactions between $\mathrm{Pu}(\mathrm{VI})$ and $\mathrm{Pu}(\mathrm{V})$ with manganese oxide minerals manganite and hausmannite," to be published.

16) J. M. Cleveland, The Chemistry of Plutonium (American Nuclear Society, Illinois, 1979), p. 82. 